\title{
An Unusual Case of Efferent Limb Obstruction Following Gastrojejunostomy
}

Dr. Ashok Kumar Sarker

Assistant Professor, Department of Surgery, Enam Medical College and Hospital, Enam Medical College Jame Mosque, Savar Union, Bangladesh

DOI: $\underline{10.36347 / \text { sjams.2020.v08i11.039 }}$

| Received: 20.10 .2020 | Accepted: 04.11.2020 | Published: 28.11.2020

*Corresponding author: Dr. Ashok Kumar Sarker

Abstract

Efferent loop obstruction is a very rare postgastrectomy obstruction that can occur following Billroth-II or Roux en- Y reconstruction. The most common loop obstruction after gastric surgery is afferent loop obstruction; however, efferent loop obstruction has been reported in rare cases. Here, we report a case of efferent loop obstruction that occurred after gasrtojejunostomy for Gastric outlet obstruction underwent 30 years back. The efferent loop obstruction was successfully resolved by laparotomy.

Keywords: Efferent loop obstruction; Phytobezoar, Gastrojejunostomy.

Copyright $\odot$ ( 2020 The Author(s): This is an open-access article distributed under the terms of the Creative Commons Attribution 4.0 International License (CC BY-NC 4.0) which permits unrestricted use, distribution, and reproduction in any medium for non-commercial use provided the original author and source are credited.

\section{INTRODUCTION}

The efferent-loop obstruction in a narrow sense refers only to obstruction of the efferent jejunal loop after gastric resection or simple gastro-enterostomy; it occurs hours or years after operation and varies greatly in symptoms and chronicity. The efferent-loop obstruction is less frequent than the afferent-loop obstruction and generally occurs as a result of internal hernia. Two forms can be distinguished: an acute and a chronic. In the acute form, internal hernia may be a consequence especially of technical problems to do with the anastomosis at surgery, including large intraoperative invagination at the suture line. The often-cited oedemas of the anastomosis and cord formation immediately below the gastrojejunostomy are rare. The later-occurring forms of the efferent-loop obstruction may be caused by ulcerations in the region of anastomosis, scarred stenosis, old adhesions, hernias of the efferent or the afferent or both loops, or by jejunogastric invagination [1]. Gastric bezoars are a form of concretion resulting from the accumulation of ingested materials. They are relatively rare and are found in less than $1 \%$ of patients undergoing gastroscopy [2]. Generally, gastric phytobezoars are common in patients with dentition problems, impaired digestion, decreased gastric motility and previous gastric surgery [3]. They usually have a wide range of clinical presentations from abdominal discomfort and weight loss to small bowel obstruction [4]. The clinical symptoms of the acute forms of efferent-loop obstruction are characterised by abdominal cramps, which are mostly localised around the umbilicus. The patients vomit large volumes of fluid which contains bile and food particles. Clinical examination reveals a tympanous abdomen, but no palpable resistance. Also, jejunogastric invagination is in most cases characterised by acute symptoms accompanied by blood vomiting. In this type of acute efferent-loop obstruction a mass is palpable in the upper abdomen in most cases; the diagnosis is verified by an upper GI series. The more chronic types show attacks of vomiting, similar to the symptoms of the afferent-loop obstruction. Only the admixture of food particles or large volumes of bile may be indicative of an efferent-loop obstruction. The signs and symptomes of both loop obstructions may be similar and difficult to distinguish, and surgical treatment is usually required to correct these problems. A phytobezoar is one of the intraluminal causes of gastric outlet obstruction, especially in patients with previous gastric surgery and/or gastric motility disorders. Before the proton pump inhibitor era, vagotomy, pyloroplasty, gastrectomy and gastrojejunostomy were commonly performed procedures in peptic ulcer patients. One of the sequelae of gastrojejunostomy is phytobezoar formation. However, a bezoar causing gastric outlet obstruction is rare even with giant gastric bezoars. This report describes about a person who presented with features of efferent loop obstruction who underwent gatsrojejunostomy 30 years back.

\section{Case Report}

A 70-year-old man presented with central abdominal pain and vomiting after meal for last 6 
months. Initially he used to vomit few hours after food intake but recently for last one month he vomits within few minutes after taking meal. The vomitus contained undigested food particle and copious amount of bile. He underwent gastrojejunostomy almost 40 years back due to pyloric stenosis following chronic duodenal ulcer but no definite document was available. Clinical examination reveals moderate dehydration and mild pallor. No lump was palpable in the abdomen. He was resuscitated with Intravenous fluids; NG tube was inserted through which large amount of undigested food particles mixed with bile came out. Initially he was put was conservative treatment during which it was observed that daily copious NG effluent was being drained indicating strongly obstruction at the efferent loop. Barium meal $\mathrm{x}$ ray was done (Figure-1) which showed a persistent partial filling defect at the proximal efferent loop through which the dye passed with difficulty.

After resuscitation he was operated. After laparotomy it was found that a hard intraluminal lump with doughy feeling palpable in the jejunum of efferent loop $40 \mathrm{~cm}$ distal to gastro jejunostomy site (Figure-2). No other abnormality was detected. Enterotomy was done A oval shaped well organized bezoar (Figure-3) was noticed which was taken out and the enterotomy wound was repaired primarily. Abdominal wound closed keeping a drain in situ. His post operative recovery was uneventful. Diet was resumed from $5^{\text {th }}$ POD on ward and was discharged on $8^{\text {th }}$ POD.

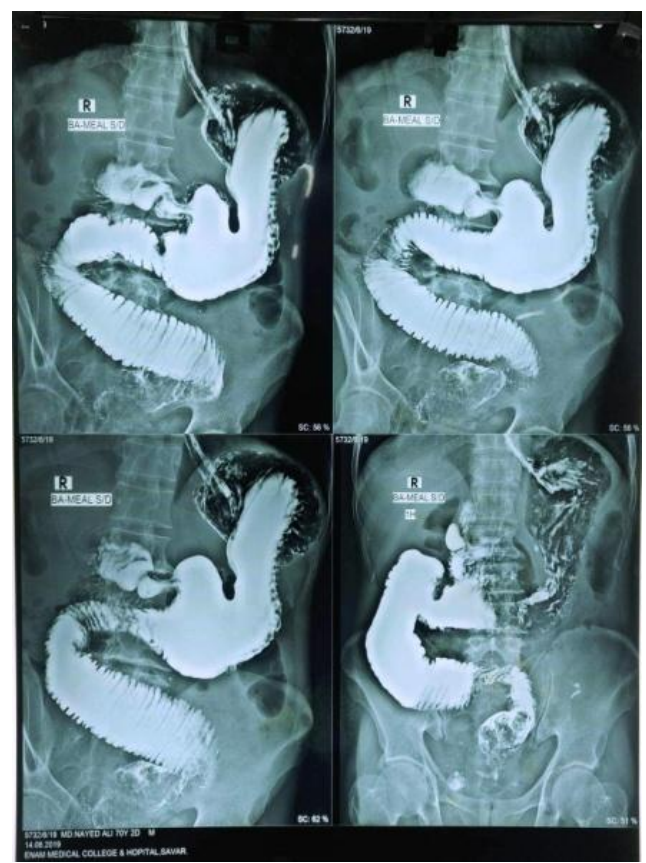

Fig-1: Barium Meal X ray of stomach and duodenum (arrow mark site of obstruction)

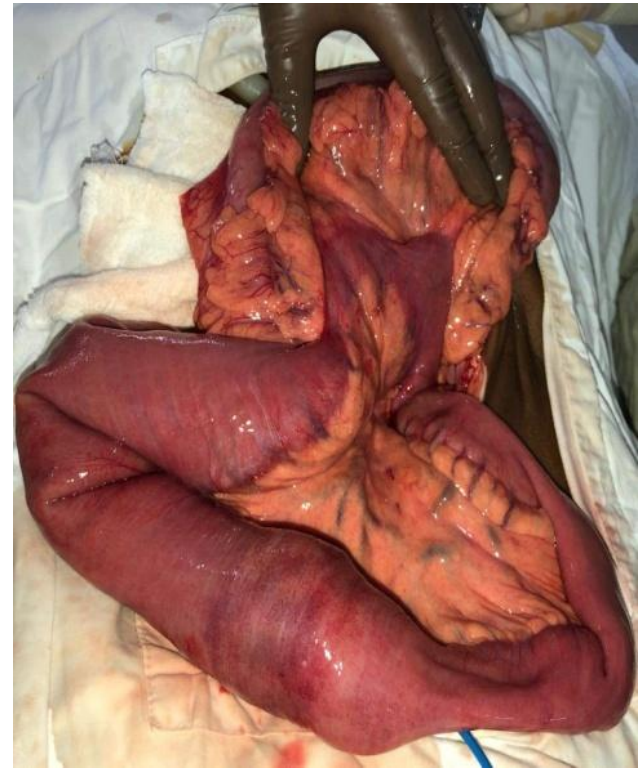

Fig-2: Hard lump (arrow) in the efferent loop, distal collapsed bowel

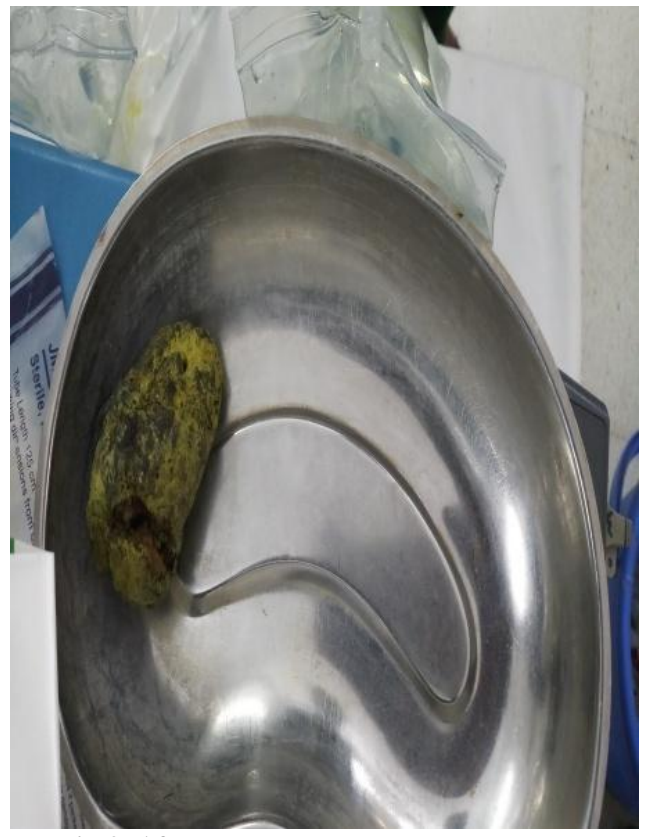

Fig-3: After enterotomy the bezoar taken out

\section{DISCUSSION}

Afferent or efferent loop obstruction is a purely mechanical problem characterized by the obstruction of gastric emptying at or near the site of a gastrojejunostomy [5]. Efferent loop obstruction is a rare post gastectomy obstruction, while afferent loop obstruction is more common [6]. The major cause of obstruction is an intestinal hernia. The more minor causes include an adhesive band and kinking because of scarring or poor reconstruction during gastric surgery [7, 8]. In some cases, intussusception causes efferent loop obstruction [9]. Rarely do we experience efferent loop obstruction with mucosal prolapsed-like stenosis of efferent loop due to adhesion or bowel edema. The commonest type of bezoar is a phytobezoar which is 
composed of vegetable material [10]. In our case, the bezoar was made up of completely meshed particles. He had loss of tooth and inadequate mastication could be the cause this bezoar formation. The pathogenesis of bezoar formation is usually intricate. It involves many factors such as improper mastication, dentition problems, alterations in the production of acid, pepsin and mucus, previous gastric surgery and impairments in gastric motility [11, 12]. Robles et al., [13] pointed out that $20 \%$ of patients have mastication and dentition problems, $70 \%-94 \%$ have had previous gastric surgery and $40 \%$ have a history of excessive dietary fiber intake. Most adults with phytobezoars are men between the ages of 40 and 50 years, however, trichobezoars usually occur in young women with psychiatric problems [14]. Patients with gastric bezoars may remain asymptomatic for many years. Common symptoms usually include abdominal pain, nausea, and vomiting, early satiety, anorexia and weight loss. Leung et al., [15] reported a case of bezoar-induced gastric outlet obstruction in a patient who had a previous gastrojejunostomy for peptic ulcer disease in whom they found a stricture at the anastomotic site. In another study, a large bezoar was found to occlude the afferent loop of the gastrojejunostomy, this patient also had afferent loop obstruction which was diagnosed by ultrasound and computed tomography (CT). In our report, the patient vomited old food indicating a gastric outlet obstruction; however, the presence of bile meant that the afferent loop of the gastrojejunostomy was still patent. The treatment of efferent loop obstruction varies depending on the cause of the obstruction. Complete loop obstruction due to a mechanical cause requires surgical intervention. Surgical interventions are numerous. However, if the obstruction is caused by an anastomotic ulcer or edema and adhesion, conservative treatment is indicated. Conservative treatments include nasogastric drainage, keeping non per os, prescribing $\mathrm{H} 2$ antagonist or proton pump inhibitors, and total parenteral nutrition. Surgical removal should be considered in patients who fail conservative therapy, have large bezoars which hinder endoscopic removal or have complications such as obstruction with underlying mechanical problems, as seen in Edmund Leung's study, and associated peptic ulcer bleeding [15]. Many studies have shown successful dissolution of gastric bezoars using agents such as Coca-cola, acetylcystine, cellulase, meat tenderizer and hydrogen peroxide [1619]. Endoscopic management as the mainstream treatment includes (biopsy and alligator forceps, lithotripters, needle cutter, snares of polypectomy, and lithotripsy with Nd: YAG laser-ignited mini-explosive procedure) [20, 21]. However, surgical management is the best technique for bigger ones. Recently, a laparoscopic procedure with Alexis wound retractor was effectively used in the management of bezoars [22, 23]. More recently, holmium: YAG (Ho: YAG) laser lithotripsy for giant bezoar and a laparoscopic technique with endobag in the stomach to prevent bezoar spillage have shown promising results [21].

\section{CONCLUSION}

Efferent loop obstruction following after a gastrectomy can be diagnosed by meticulous history taking, physical examination, and radiologic modalities. Phytobezoars are a rare cause of gastric outlet obstruction, especially in patients with previous gastrojenunostomy. Currently, gastroscopy is the best method for detecting and managing gastric bezoars by endoscopic removal. Some cases require surgical removal, especially those associated with complications. The most important points in the management of a bezoar are identification of the causative factor and prevention of recurrence by counseling.

\section{REFERENCES}

1. Kadian RS, Rose JF, Mann NS. Gastric bezoars-spontaneous resolution. Am Gastroenterol. 1978;70(1):79-82.

2. Mir AM, Mir MA. Phytobezoar after vagotomy with drainage or resection. $\mathrm{Br}$ J Surg. 1973;60(11):846-849.

3. Calabuig R, Navarro S, Carrió I, Artigas V, Monés J, Puig LaCalle J. Gastric emptying and bezoars. Am J Surg. 1989;157(3):287-290.

4. De Bakey M, Ochsner A. Bezoars and concretions: a comprehensive review of the literature with an analysis of 303 collected cases and a presentation of 8 additional cases. Surgery. 1939;5(1):132-160.

5. Shchepotin IB, Evans SR, Chorny VA, Shabahang M, Buras RR, Nauta RJ. Postoperative complications requiring relaparotomies after 700 gastretomies performed for gastric cancer. Am J Surg. 1996; 171(2): 270-273.

6. Jordan GL. Surgical management of postgastrectomy problems. Arch Surg. 1971; 102(4): 251-259.

7. Cleator IG, Falconer CW, Small WP, Smith AN. Cause of stomal obstruction after gastroenterostomy. Br Med J. 1968; 2(5604): 530532.

8. Pickleman J, Lee RM. The management of patients with suspected early postoperative small bowel obstruction. Ann Surg. 1989; 210(2): 216219.

9. Kwak JM, Kim J, Suh SO. Anterograde jejunojejunal intussusceptions resulted in acute efferent loop obstruction after subtotal gastrectomy. World J Gastroenterol. 2010; 16(27): 3472-3474.

10. Holloway WD, Lee SP, Nicholson GI. The composition and dissolution of phytobezoars. Arch Pathol Lab Med. 1980;104(3):159-161.

11. White NB, Gibbs KE, Goodwin A, Teixeira J. Gastric bezoar complicating laparoscopic adjustable gastric banding, and review of literature. Obes Surg. 2003;13(6):948-950.

12. Ahn YH, Maturu P, Steinheber FU, Goldman JM. Association of diabetes mellitus with gastric 
bezoar formation. Arch Intern

Med. 1987;147(3):527-528.

13. Robles R, Parrilla P, Escamilla C, Lujan JA, Torralba JA, Liron R, Moreno A. Gastrointestinal bezoars. Br J Surg. 1994; 81(7):1000-1001.

14. Balik E, Ulman I, Taneli C, Demircan M. The Rapunzel obstruction: a case report and review of the literature. Eur J Pediatr Surg. 1993;3(3):171173.

15. Leung E, Barnes R, Wong L. Bezoar in gastrojejunostomy presenting with symptoms of gastric outlet obstruction: a case report and review of the literature. J Med Case Reports. 2008; 2:323.

16. Walker-Renard P. Update on the medicinal management of phytobezoars. Am J Gastroenterol. 1993; 88(10):1663-1666.

17. Schlang HA. Acetylcysteine in removal of bezoar. JAMA. 1970;214(7):1329.

18. Ladas SD, Triantafyllou K, Tzathas C, Tassios P, Rokkas T, Raptis SA. Gastric phytobezoars may be treated by nasogastric Coca-Cola lavage. Eur J Gastroenterol Hepatol. 2002; 14(7):801-803.
19. Kato H, Nakamura M, Orito E, Ueda R, Mizokami $M$. The first report of successful nasogastric CocaCola lavage treatment for bitter persimmon phytobezoars in Japan. Am

Gastroenterol. 2003;98(7):1662-1663

20. Ugenti I, Travaglio E, Lagouvardou E, Iambrenghi OC, Martines G. Successful endoscopic treatment of gastric phytobezoar: A case report. Int J Surg Case Rep. 2017;37(C):45-47.

21. Grande G, Manno M, Zulli C, Barbera C, Mangiafico S, Alberghina N, Conigliaro RL. An alternative endoscopic treatment for massive gastric bezoars: Ho: YAG laser fragmentation. Endoscopy. 2016;48(S 01):E217-.

22. Tudor ECG, Clark MC. Laparoscopic-assisted removal of gastric trichobezoar; a novel technique to reduce operative complications and time. Journal of Pediatric Surgery. 2013;48(3):e13- e15.

23. Parakh JS, McAvoy A, Corless DJ. Rapunzel obstruction resulting in gastric perforation. Ann R Coll Surg Engl. 2016; 98(1): e6- e7. 